link between civilization and the rest of Nature are largely lost.

The bond with Nature, once broken, can only be mended by losing ground already won and then attempting to recover it. It is improbable that any people which has fought and won its battle will willingly retreat in order to fight again. The peoples of Western Europe hold their lands securely against the forests they have supplanted, and only a few men are now needed to protect the strong defences that have been erected against wild Nature. The bodily drift from the land may be stemmed, but the spiritual drift will go on There is no longer any biological restraint to bind the great majority of men to the soil, and economic remedies are no substitute for the harsh bond of biological necessity that is now lacking. The pain and travail, the wind and rain in the fields, which are the essence of Nature's bond, are not for the economists and sociologists nor-if they can be avoided-for anybody else.
In America, on the other hand, the recently vaunted conquest of Nature by technocracy has been shown to be unreal. Desolation and destruction of the land have forced a retreat which can only be reversed by a people deeply rooted in the soil. The present drift from the land must be stopped and a spiritual bond forged between man and Nature. But the bond will be forged not by lightening the hard lot of the farmer, nor by otherwise encouraging a shallow-rooting human cover on the land, but by an unremitting struggle against the natural forces of adversity that mankind has released upon itself. Those forces are of biological and physical origin, and can be overcome-and the enduring fertility of the soil assured-only by biological and physical effort. The economics of the struggle with, and of the victory over, Nature are of great practical importance, particularly in these critical times, but they are not fundamental to the ultimate issue. G. V. JACKS.

\title{
STUDIES IN MICROBIOLOGY
}

A Textbook of Microbiology

By Prof. Kenneth L. Burdon. Second edition of "A Textbook of Bacteriology". Pp. xv +638 . (New York: The Macmillan Company, 1939.) 14s. net.

So far from being a text-book on general $S$ microbiology, as the title seems to imply, more than half this book is devoted to the medical aspects of the subject, little space being assigned to fermentation, soil microbiology and nitrification, micro-organisms in industry, and the like.

In the earlier portion of the book, some 150 pages, the fundamentals of microbiology are dealt with at some length, and an excellent account is given of the general properties and elassification of micro-organisms, with chapters on the Protozoa, fungi and moulds, spirochætes and viruses, and the true bacteria. Part 2 is devoted to the laboratory study of micro-organisms-the microscope, culture media and culture methods, and isolation, with a section on disinfection. Under viruses and filterable micro-organisms, no explanation is given of the reason for their invisibility microscopically.

The remainder of the book gives an account of the relation of micro-organisms to disease, commencing with the sources and prevention of infection and aseptic technique. Chapters follow on resistance and immunity, anaphylaxis, and the practical use of vaccines and serums. Lastly, the microbiology of the chief infective diseases is considered. The treatment here is on somewhat novel lines, for the individual diseases are dealt with from the point of view of the regions of the body principally affected, the natural microbial flora of the region and the pathological conditions affecting the part being first considered, after which the micro-organisms responsible for these conditions, or likely to be present, are described.

The descriptions given throughout are clear and accurate and well up to date, and the treatment of the subject takes a middle course between an elementary text-book and an advanced treatise. We gather that the book has been designed as a general college course on the subject, rather than for the student of medicine and hygiene, and while serving as a useful outline for the medical student, it is scarcely full enough in many sections to be his only guide. As in many American textbooks, review questions are appended to the various chapters, and the book concludes with appendixes on bibliography, formulæ, and suggested laboratory exercises.

The book is very readable and free from mistakes, is well produced and illustrated, and some portraits of pioneers of the subject add to its attractiveness.

\section{R. T. Hewlett.}

